\title{
Avaliação neurológica de cães infectados naturalmente pelo vírus da cinomose canina
}

\author{
[Neurological evaluation of dogs naturally infected by canine distemper virus]
}

\section{"Artigo Científico/Scientific Article"}

\author{
Evanária Cruz Aguiar ${ }^{1}$, Tiago da Silva Teófilo ${ }^{2}$, Anderson Cássio Campelo Costa ${ }^{1}$, \\ Nathálya dos Santos Martins ${ }^{3}$, Renata Mondego Oliveira ${ }^{3}$, Isadora de Fátima Braga Magalhães ${ }^{4}$, \\ Mylena Andréa Oliveira Torres ${ }^{5 *}$
}

\author{
${ }^{1}$ Médico Veterinário Autônomo, São Luís-MA, Brasil. \\ ${ }^{2}$ Programa de Pós-Graduação em Ciência Animal, Universidade Federal Rural do Semi-Árido (UFERSA), Mossoró- \\ RN, Brasil. \\ ${ }^{3}$ Rede Nordeste de Biotecnologia-RENORBIO (UFMA), Ponto focal Maranhão, São Luís-MA, Brasil. \\ ${ }^{4}$ Laboratório de Histologia, Universidade Federal do Maranhão (UFMA), Pinheiro-MA, Brasil \\ ${ }^{5}$ Departamento do Curso de Medicina, Universidade Ceuma (UNICEUMA), São Luís-MA, Brasil. \\ *Autor para correspondência/Corresponding author: E-mail: mylena.torres@ hotmail.com
}

\begin{abstract}
Resumo
A cinomose canina está difundida por todo o mundo e é uma das doenças virais mais graves e fatais em cães domésticos podendo acometer outros carnívoros. É uma doença multissistêmica, causa sinais clínicos respiratórios, gastrointestinais, cutâneos e neurológicos que podem ocorrer simultaneamente ou não, sendo a fase neurológica a mais grave e preocupante, pois na maioria das vezes o animal vem a óbito. Objetivou-se avaliar os sinais neurológicos da cinomose canina. Foram coletados dados de 20 cães oriundos dos atendimentos do Hospital Veterinário da Universidade Estadual do Maranhão - HOVET/UEMA, São Luís, MA, Brasil, no período de junho a novembro de 2015, que apresentavam sinais clínicos neurológicos e eram positivos para cinomose. Para análise dos dados foi utilizada estatística descritiva simples e foi verificado que dos 20 animais avaliados, os sinais neurológicos mais frequentes foram: mioclonia (80\%), depressão e apatia (75\%), ataxia (75\%) e hipertonia e espasticidade nos músculos (35\%). Por meio do exame clínico e da observação das reações comportamentais dos cães estimou-se que os nervos cranianos mais afetados foram os Trigêmio (65\%), Oculomotor (35\%) e Acessório (25\%). Concluímos que a cinomose canina causa grandes transtornos nervosos devido aos nervos afetados. Além disso, foram observadas alterações comportamentais e sequelas evidentes nos cães que sobrevivem à fase neurológica da doença.
\end{abstract}

Palavras-Chave: vírus; fase neurológica; nervos cranianos.

\begin{abstract}
Canine distemper is spread throughout the world and is one of the most serious and fatal viral diseases in domestic dogs which can affect other carnivores. As a multisystemic disease, it causes respiratory, gastrointestinal, cutaneous, and neurologic signs that may occur simultaneously or not, and the neurologic phase is the most serious and concerning because most of the time the animal dies. The objective was to evaluate the neurologic signs of distemper, in order to identify the most affected cranial nerves. Data were collected from 20 dogs in the neurologic phase of the disease examined at the "Hospital Veterinário da Universidade Estadual do Maranhão" - HOVET/UEMA, São Luís, MA, Brazil, in the period from June to November 2015, with the help of medical records. Descriptive statistics was used for data analysis, where it was found that of the 20 evaluated animals, the most prevalent neurologic signs were myoclonia (80\%), depression and apathy (75\%), ataxia (75\%), and hypertonia and muscles spasticity (35\%). It was also observed that the most affected cranial nerves were the trigeminal (65\%), oculomotor (35\%), and accessory (25\%). This way, canine distemper causes major nervous disorders due to the affected nerves. Besides, behavioural changes and sequelae were observed in dogs which survived the neurological phase of the disease.
\end{abstract}

Keywords: virus; neurologic phase; cranial nerves. 


\section{Introdução}

A cinomose, uma doença altamente infecciosa e contagiosa, é uma enfermidade viral cujo agente pertence à família Paramyxoviridae e ao gênero Morbillivirus (Silva et al., 2009). O cão é o reservatório mais frequente do vírus da cinomose, sendo também seu maior disseminador. Contudo, o vírus pode acometer várias espécies de carnívoros e animais selvagens (Norris et al., 2006).

O vírus da cinomose canina (VCC) acomete cães de todas as idades, raças e sexos, tendo maior predileção por filhotes e indivíduos não vacinados (Martella et al., 2008). Os cães susceptíveis são infectados inicialmente através da inalação de aerossóis ou ingestão de gotículas infectantes, presentes nas secreções nasal e ocular, que apresentam grande quantidade de partículas virais. Depois de infectados, os animais podem apresentar lesões nos sistemas respiratório, digestório e neurológico, podendo apresentar também lesões dermatológicas e oftálmicas (Greene, 2015).

Dentre os sinais neurológicos mais observados estão às alterações de comportamento, apatia, ataxia, paraplegia, tetraplegia, paralisias de mandíbula, vesícula urinária e do reto, vocalização similar à do estado de dor, mioclonias, convulsões e coma (Amude et al., 2006).

A avaliação do comprometimento dos 12 pares de nervos cranianos (NC) ligados ao encéfalo é uma parte importante do exame neurológico. Anormalidades ou lesões nos NCs podem acarretar grandes danos e até perda da função de algumas estruturas (Lorenz e Kornagay, 2006).

Várias doenças que acometem cães apresentam sinais clínicos neurológicos, dentre elas a ehrlichiose canina, cinomose, raiva e a meningoencefalocele congênita. Quando o animal apresenta a forma neurológica da cinomose, mas sobrevive ao tratamento, geralmente apresenta sequelas. De acordo com o grau avançado dos sinais clínicos e o comprometimento dos órgãos, o cão pode vir a óbito. Diante do exposto, objetivouse com este estudo avaliar os sinais neurológicos mais frequentes em cães acometidos pelo VCC e quais os nervos cranianos mais lesionados.

\section{Material e Métodos}

A amostra foi constituída de 20 cães, provenientes do atendimento do Hospital Veterinário "Francisco Edilberto Uchôa Lopes" (HOVET), da Universidade Estadual do Maranhão (UEMA), São Luís, MA no período de junho a novembro de 2015. Foram escolhidos os animais positivos no teste rápido Alere ${ }^{\circledR} \mathrm{Ab}$ para cinomose e que apresentaram sinais neurológicos, independente de idade, sexo e raça.

Todos os animais foram submetidos à avaliação semiológica detalhada segundo Feitosa et al. (1997) e Feitosa (2014), onde foram identificados individualmente por meio de uma ficha clínica. $\mathrm{Na}$ avaliação neurológica, foram avaliados os sinais: estado mental, postura, marcha, reações posturais, avaliação dos nervos cranianos pela palpação e sensibilidade à dor, sendo o escore corporal definido de acordo com os sinais clínicos neurológicos apresentados.

Os tutores de todos os cães que participaram da pesquisa foram informados a respeito dos procedimentos adotados e assinaram um termo de consentimento livre e esclarecido.

Os dados coletados foram tabulados no programa Microsoft Office Excel 2010, utilizandose cálculos e construções de gráficos, para posterior análise estatística descritiva simples.

\section{Resultados}

Dos 20 cães atendidos no Hospital Veterinário com histórico de cinomose na fase neurológica da doença, 95\% (18) não tinham sido vacinados contra cinomose, 84\% (16) dos cães tinham em seu histórico de vacinação apenas a vacina antirrábica, fornecida pelo governo, $16 \%$ (3) dos animais nunca haviam sido vacinados e $5 \%$ (1) o proprietário não soube informar sobre a vacinação.

Em relação ao estado mental, 75\% (15) dos animais apresentaram-se deprimidos e apáticos, enquanto $25 \%$ (5) estavam em estado de alerta. A frequência da marcha foi também avaliada nesse estudo, e o resultado foi que $75 \%$ (15) dos cães avaliados apresentaram ataxia, que consistiu na ausência de coordenação dos movimentos voluntários, e desses animais $15 \% \quad$ (3) apresentavam movimentos sem coordenação e caiam após algum tempo. Alguns dos animais avaliados não conseguiam mais se locomover. Somente $10 \%$ (2) foram considerados normais em relação à marcha e apenas um animal apresentou ataxia com andar em círculo aberto (Figura 1).

Foi realizado exame físico em todos os animais e foi observado durante a palpação que $35 \%$ (7) estavam com hipertonia e espasticidade nos músculos, 25\% (5) estavam com hipotonia, $15 \%$ (5) apresentaram atonia e $25 \%$ (5) dos animais 
avaliados foram considerados normais quanto à palpação. Na avaliação da postura as alterações vistas com maior frequência nos cães examinados foram tremores involuntários, oscilações da cabeça e paresia dos membros pélvicos (Figura 2).

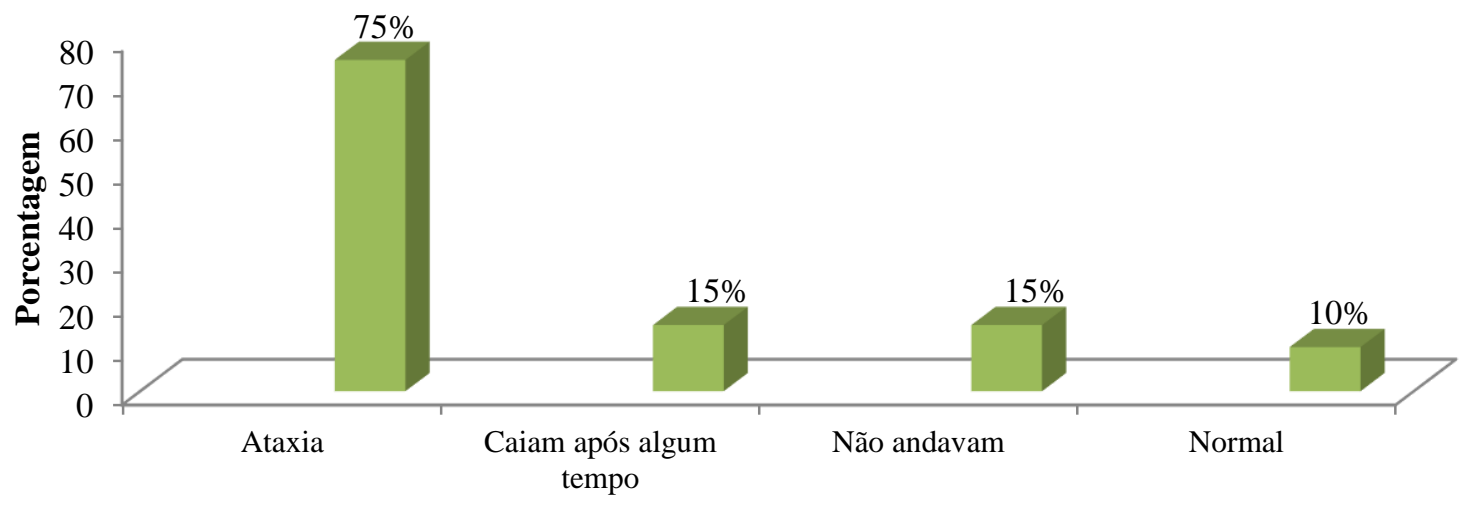

Figura 1. Percentual do estado da marcha de cães com cinomose atendidos no Hospital Veterinário (HOVET) da Universidade Estadual do Maranhão (UEMA), São Luís, MA.

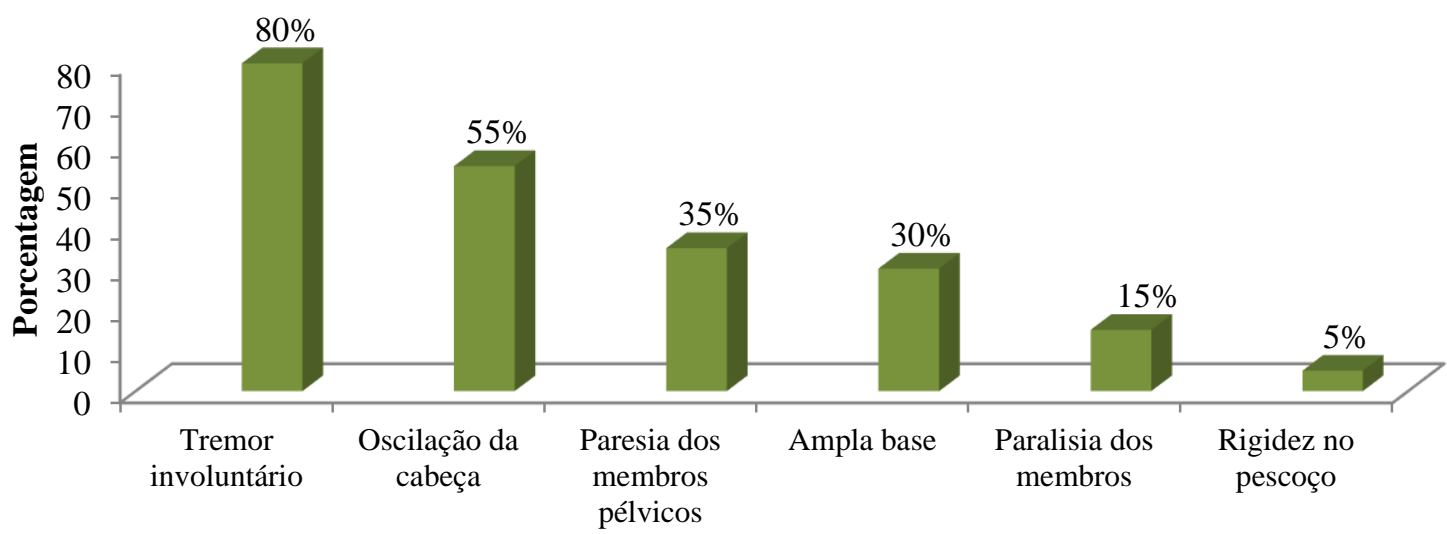

Figura 2. Frequência dos sinais neurológico em relação à postura de cães com cinomose atendidos no Hospital Veterinário (HOVET) da Universidade Estadual do Maranhão (UEMA), São Luís, MA.

Em relação à sensação de dor, foi observado que os cães apresentaram dor profunda pela pressão vigorosa sobre o periósteo da região interdigital e dor superficial com e sem estímulo tátil a nível cutâneo, como resposta a sensibilidade elevada ao estímulo (Figura 3).

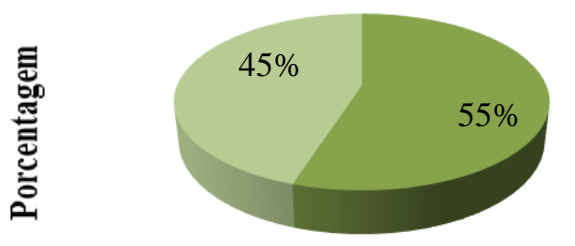

$\square$ Dor superficial $\square$ Dor profunda

Figura 3. Percentual quanto a sensação de dor em cães com cinomose atendidos Hospital Veterinário (HOVET) da Universidade Estadual do Maranhão (UEMA), São Luís, MA.
No presente estudo, a vocalização ocorreu em 25\% (5) dos casos avaliados e verificou-se a sinal clínico de dor sem precisar provocar estímulos no animal. Os sinais clínicos neurológicos mais prevalentes foram mioclonias, ampla base, paresia dos membros, paralisia, alterações na visão, ataxia e vocalização.

Os animais foram avaliados quanto às reações posturais e a maioria dos animais não conseguiu realizar testes como caminhar de forma unilateral, ficar em estação unilateral e saltitar. Foram feitas avaliações nos animais de maneira a identificar possíveis lesões nos nervos cranianos e estimou-se que os mais afetados pelo VCC foram os nervos trigêmio $65 \%$ (13), oculomotor 35\% (7) e acessório $25 \%$ (5). As lesões nos nervos trigêmeos foram observadas através da avaliação da sensibilidade facial, onde realizou-se estímulos de toque na face dos animais em diferentes regiões 
com uma pinça hemostática e não foi observado a contração da musculatura facial e o fechamento das pálpebras. Para avaliação de lesões nos nervos oculomotores foi realizado o teste do reflexo pupilar em ambiente escuro. Os olhos dos animais eram previamente cobertos para que houvesse midríase e após, avaliou-se a resposta à luz. Realizou-se também o teste do reflexo palpebral, com um estímulo tátil suave nos cantos medial e lateral das pálpebras com os dedos, e não houve observação dos animais fechando as pálpebras. A lesão nos nervos acessórios se deu pela observação de hipotrofia da musculatura do trapézio.

No presente estudo $20 \%$ (4) dos cães foram eutanasiados devido a complicações neurológicas que deixaram os animais inabilitados e com lesões incompatíveis com a vida, com constante vocalização e gemidos caracterizando sinal clínico de dor e paralisia completa com incapacidade de realizar movimentos como caminhar. Dos animais avaliados neste estudo, apenas $10 \%$ (2) apresentaram cinomose crônica com sequelas, como mioclonias e rigidez dos membros posteriores; e $10 \%$ (2) estavam apresentando a sintomatologia da cinomose pela segunda vez.

\section{Discussão}

Diversos sinais neurológicos são associados à infecção pelo VCC e sua manifestação varia de acordo com a área do SNC afetada (Greene e Appel, 2006). Galán et al. (2014) observaram em estudos que em cães vacinados e diagnosticados com cinomose, pode haver ataxia moderada e diminuição da propriocepção. Mangia e Paes (2008) avaliaram reações posturais e marcha e $40 \%$ (4) dos cães com cinomose apresentavam ataxia, enquanto que, Silva (2009) observou esse mesmo sinal clínico em 25\% (155) dos animais.

Distúrbios neurológicos causam muita dor a qual gera consequências metabólicas, fisiológicas e consequentemente comportamentais. Segundo Lorenz e Kornagay (2006) a dor profunda provoca alterações no comportamento do animal, enquanto a dor superficial é discriminatória permitindo a percepção da localização exata do estímulo. É observado dor espinhal ou neuropática devido ao envolvimento das meninges, raízes nervosas e os nervos periféricos, sendo por isso indicado o uso de analgésicos durante o tratamento (Neves et al., 2010).

Silva et al. (2009), Amaral et al. (2008) e Campos et al. (2013) também observaram em seus estudos a vocalização em 3,5\% (22), 35\% (16) e
10\% (8) dos cães respectivamente. Em pesquisas feitas por Galán et al. (2014) os sinais neurológicos predominantes foram convulsões, paralisia dos membros pélvicos, sinais vestibulares, como ataxia e nistagmo e cerebelares como tremores e hipermetria. As reações posturais são mecanismos complexos que possibilitam que o animal caminhe e mantenha-se em estação, alterações em dois ou mais testes em qualquer membro indica uma deficiência significativa, mas não indica a localização exata da lesão (Coelho et al., 2013).

Silva et al. (2009) afirmaram que transtornos neurológicos avançados e progressivos tornam o animal vulnerável, podendo leva-lo a óbito. Quando o VCC atinge o SNC o animal pode vir a morte em curso agudo ou crônico e se eventualmente conseguir inibir o vírus $\mathrm{e}$ sobreviver, sempre fica com sequelas irreversíveis.

\section{Conclusão}

$\mathrm{Na}$ fase neurológica da doença, o vírus da cinomose afeta os nervos cranianos, que levam a transtornos neurológicos e dor. Os nervos mais afetados foram os nervos trigêmio, oculomotor e acessório, seguindo de alterações comportamentais e sequelas nos cães que sobrevivem à essa fase dessa enfermidade.

\section{Conflito de Interesse}

Os autores declaram não existir conflito de interesse.

\section{Comitê de Ética}

O presente estudo não necessitou da submissão ao Comitê de Ética Animal, pois foi feito somente acompanhamento clínico dos animais atendidos no Hospital Veterinário (HOVET) da Universidade Estadual do Maranhão (UEMA), São Luís, MA.

\section{Agradecimentos}

Ao Hospital Veterinário "Francisco

Edilberto Uchôa Lopes" (HOVET) da Universidade Estadual do Maranhão.

\section{Referências}

Amaral, H.A.; Cortez, A., Richtzenhain, L.J.; Funada, M.R.; Soares, R.M.; Durigon, E.L.; Larsson, M.H.M.A. PCR detection of canine distemper vírus in biological fluids. Journal of Veterinary Research, 12(2):7075, 2008. 
Amude, A.M.; Alfieri, A.A.; Alfieri, A.F. Clinicopathological findings in dogs with distemper encephalomyelitis without characteristic signs of the diseases. Research in Veterinary Science, 82:416-422, 2006.

Campos, C.G.; Lopes, L.L.; Lima, S.R.; Docal, C.R. Vírus da Cinomose Canina na Região Centro Oeste do Brasil. Archives of Veterinary Science, 18(3):751-753, 2013.

Coelho, M.P.R.C.; Gutierrez, J.S.; Martins, B. de C. Cadernos Técnicos de Veterinária e Zootecnia, 69(2):7-25, 2013.

Feitosa, M.M.; Feitosa, F.F.F.; Kohayagawa, A.; Curi, P.R.; Mogami, S.R.K. Avaliação física, citológica, de proteínas e determinação qualitativa de globulinas do líquor de cães normais e com encefalites por cinomose. Brazilian Journal Research and Animal Science, 34:147-151, 1997.

Feitosa, F.L.F. Semiologia veterinária: A arte do diagnóstico $-3^{\circ}$. Ed. - São Paulo; Roca, 2014, p. 640.

Galán, A.; Gamito, A.; Carletti, B.E.; Guisado, A.; de las Mulas, J.M.; Pérez, J.; Martín, E.M. Uncommon acute neurologic presentation of canine distemper in 4 adult dogs. The Canadian Veterinary Journal, 55(4):373-8, 2014.
Greene, C.E.; Appel, M.J. Canine distemper. In: Greene C.E. (Eds). Infectious disease of the dog and cat. 3 ed., Philadelphia: Elsevier, 2006, p. 25-41.

Greene, C.E. Doenças infecciosas em cães e gatos. 4. Ed, Rio de Janeiro, Guanabara Koogan, 2015, p. 26-43.

Lorenz, M.D.; Kornegay J.N. Neurologia veterinária. 4 ed., Barueri, Manole, 2006.

Mangia, S.H.; Paes, A.C. Neuropatologia da cinomose. Veterinária e Zootecnia, 15(3):416-427, 2008

Martella, V.; Elia, G.; Buonavoglia, C.Canine Distemper Virus. Veterinary Clinics Small Animal Practice, 38:787-797, 2008.

Neves, I.V.; Tudury, E.A.; Costa, R.C. Fármacos utilizados no tratamento das afecções neurológicas de cães e gatos. Semina: Ciências Agrárias, 31(3):745-766, 2010.

Norris, J.M.; Krockenberger, M.B.; Baird, A.A.; Knudsen G. Canine distemper: re-emergence of an old enemy. Australian Veterinary Journal, 84:362-363, 2006.

Silva, M.C.; Fighera, R.A.; Brum, J.S.; Mazzanti, A.; Pierezan, F.; Barros, C.S.L. Neuropatologia da cinomose canina: 70 casos (2005-2008). Pesquisa Veterinária Brasileira, 29:643-652, 2009. 